\title{
El llarg camí del Mal Caçador. El Comte Arnau i el Barón d'Espés revisitats
}

\author{
Josefina Roma Riu \\ Universitat de Barcelona \\ j.santana@coac.net
}

\begin{abstract}
RESUM
L'anàlisi de dues figures mítiques del Pirineu, al Ripollès i a la Ribagorça, el Barón d'Espés i el Comte Arnau, ens fa veure dues històries paral-leles que comprenen, en primer lloc, el descrèdit fomentat pel poder, cap a personatges als quals es titlla de depredadors sexuals desmesurats; en segon lloc, la seva possible aliança amb el dimoni i la bruixeria, $i$, en tercer lloc, el càstig per a tota l'eternitat com un exemple del Mal Caçador, en el cas del Comte Arnau, més diluït en el Barón d'Espés, i la mort afrosa causada pels seus gats o gossos, en el cas del Barón d'Espés. Aquests personatges, però, no són més que la derivació en personatges locals, d'antigues divinitats del tipus d'Odin, conductores d'ànimes que, a través de les diverses aculturacions religioses sofertes, han estat descavalcades dels seus valors positius per enfonsar-les en l'inframón o infern, amb trets negatius, com passa generalment quan es produeix una confrontació entre dues cultures i una en surt perdedora. Però el poble ha triat per blasmar aquests personatges no la depredació sexual, sinó l'abús de poder dels nobles cap als seus vassalls.
\end{abstract}

PARAULES CLAU

Mal Caçador; Déus Psicopompos; aculturació religiosa; mals usos medievals; poblacions anteriors

\section{ABSTRACT}

The present article analyses two mythical heroes from the Pyrenean Counties of Ripollès and Ribagorça, the Baron of Espés and Count Arnau, and reveals two parallel stories based on three main features. The first is the discrediting of two noblemen, accused by political and ecclesiastical powers of being sexual predators; the second is their suspected evil alliances with the devil and with witches; and the third is the theme of punishment which, in the case of Count Arnau, meant being condemned to run in a savage hunt for all eternity, and, for the Earl of Espés, meant or being savaged to a horrible death by his dogs or cats. These characters, however, are none other than local derivations of ancient gods such as Odin, that is, psychopomps leading a host of lost souls. With the spread of newer religions, these gods were often deprived of their positive qualities and were relegated to the underworld or hell, as often occurs when one culture asserts itself over another. However, over many generations these mythical characters continued to be used by the common people to criticise the nobles not for their supposed sexual depredations but for abusing their power over their vassals.

KEYWORDS

Savage hunt; psychopomp gods; religious acculturation; medieval serf taxation; ancient populations

REBUT: IO.I2.2OI4 | ACCEPTAT: 2I.OI.2OI5

Estudis de Literatura Oral Popular, núm. 4, 20I5, 95-IO5 | DOI: IO.I7345/elop20I595-IO5

ISSN: 2OI4-7996 | http://revistes.urv.cat/index.php/elop 
Sinyor d'Espés, si a Obarra vas, a Espés no hi tornaràs més!

—En los tres gossos que porto i l'espingarda?

tornar o no tornar, io a Obarra vull anar-

A Obarra si hi va anar, però no en va tornar

(recollit per Manuel Iglesias)

-On us han donat posada, Comte l'Arnau?

A on us han donat posada, valga'm Déu val!

-A l'infern me l'han donada, muller lleial,

a l'infern me l'han donada, viudeta igual.

-Per què allí us l'han donada, Comte l'Arnau?

per què allí us l'han donada, valga'm Déu val!

-Per soldades mal pagades, muller lleial,

i mesures mal rasades, viudeta igual...

(de la cançó del Comte Arnau, popular)

EN EL CAMP DE L'ANTROPOLOGIA DEL MiTe, l'exercici de tornar una vegada i una altra a meditar sobre uns mites determinats és gairebé una obligació, perquè els mites són això, una invitació a tornar-hi, de manera que, com més estudiem i més bagatge vital adquirim, els mites se'ns manifesten més complexos i ens aporten més solucions per a l'ànima, que, en definitiva, és del que tracta el mite. ${ }^{1}$

Vull reflexionar sobre dos personatges mítics: el Barón d'Espés i el Comte Arnau. El primer, situat a la Ribagorça i el segon, al Ripollès. El Barón d'Espés no ha sortit mai del seu entorn pirinenc, ben al contrari del Comte Arnau, que, essent representatiu d'uns indrets ben concrets del Ripollès, va sobreeixir de l'univers local a causa de l'obra dels literats i músics de la Renaixença i de començaments del segle Xx que van veure en ell la possibilitat de bastir una mitologia catalana, a exemple de la mitologia germànica, celta o russa, que des del s. xix eren motiu de grans recerques per Europa. Per això, no és gens estrany que, després de la presentació de la cançó en la recerca folklòrica de Milà i Fontanals, molts escriptors com Víctor Balaguer (I86I), Àngel Guimerà (I895), Frederic Soler (I900), Joan Maragall (I900), Mn. Jacint Verdaguer (I90I), Josep Carner (I905), Josep M. de Sagarra (I928), Joan Brossa (I975) i molts altres més discrets li dediquessin obres que volien ser les tragèdies que posessin la literatura i la mitologia catalana en el nivell d'excel-lència d'altres literatures i mitologies europees del moment. Fins i tot, el Comte Arnau va ser el protagonista de diverses obres musicals i òperes que, a l'ombra dels èxits de Richard Wagner, van voler dotar la Catalunya wagneriana

I. Aquest article s'emmarca en una línia de recerca sobre literatura popular catalana que ha rebut finançament del Ministeri d'Economia i Competitivitat a través del projecte d'R+D FFI2OI2-31808. 
d'un corpus operístic. Així, Enric Morera posa la música al poema de Josep Carner, El Comte Arnau, l'any I905. Felip Pedrell ho fa amb l'obra de Joan Maragall, l'any I9II. Rossend Serra i Pagès no s'escapa d'aquesta fal·lera, i encarrega un libretto a un escriptor que el va anar fent passar amb raons, fins que li va haver de reconèixer que l'havia defraudat. El seu creixement com a figura mitològica arriba als nostres dies, en representacions de teatre musical, en realitzacions d'una sèrie televisiva i, fins i tot, en interpretacions esotèriques. Malgrat tota aquesta difusió, en l'àmbit de Catalunya continua viu com a mite local. El Barón d'Espés, en canvi, atès que només han perviscut fragments del mite, només ha interessat als estudiosos del folklore o historiadors. Així, va ser citat per Duran Gudiol en els seus estudis de l'origen dels Comtats de Sobrarb i Ribagorça, als anys seixanta del segle passat. També va ser estudiat per Manuel Iglesias, en la seva obra sobre el monestir d'Ovarra, i, sobretot, per Artur Quintana, que va recollir tota la tradició oral en el seu entorn ribagorçà.

Encara hi ha un altre personatge ribagorçà que s'atansa a les característiques del Barón d'Espés i del Comte Arnau, és Francès de Castanesa, però la informació que en tenim és molt més fragmentària que la del Barón d'Espés. La informació sobre el Comte Arnau és la més completa i ens serveix com a guia, ja que, sense la comparació amb ell, no podríem entendre l'abast del complex mitològic. D'aquesta manera, i des d'un fons comú i un desenvolupament i entorn semblants, s'han configurat les narracions que ens recorden un passat paral·lel.

No tractaré de fer un estudi historiogràfic, encara que esmenti alguns personatges citats en les fonts històriques escrites. Estem parlant de llegendes i mites, transmesos oralment, i no per aquesta raó menys veritables, encara que la seva realitat abasta també la interpretació i els avatars de les diverses generacions que els han transmès, així com la memòria i l'oblit que les acompanyen.

Del Barón d'Espés se'n coneix el seu castell o casalot; la seva dedicació a les grans obres del monestir d'Ovarra; els amors prohibits amb una dama i una monja; els tributs i treudes als seus vassalls, dels quals només es lliurava l'antiga casa de la Mora, que només havia de donar-li un got d'aigua, anualment, ja que el van socórrer quan estava molt assedegat, i sobretot, es coneix la seva mort, atribuïda, a vegades, al dimoni o a les «bruixes» del Turbón, que van fer embogir els seus gossos, com narren algunes versions de la història.

Del Comte Arnau, baró de Mataplana, se'n coneixen moltes històries: les seves relacions amb les monges de Sant Amanç i les sacrílegues amb una monja difunta; les seves correries llibertines pels túnels naturals que cusen tota la comarca; la seva penitència en el petit castell de Mataplana; el seu ajut en la construcció de Sant Pere de Ripoll, de les escales tallades a la roca, del Santuari de Montgrony, de la seva afecció per la cacera, que li fa abandonar la missa en el moment de la consagració per perseguir una peça; el seu intent de modificar el curs del riu Llobregat; els enganys i mals usos amb els seus vassalls, i la seva relació amb les fades i encantàries. Se li atribueix un pacte amb el dimoni, l'aliança amb Epidòfer per trobar un elixir de llarga vida; la seva mort, causada pels seus gats, que l'arrosseguen a l'infern; l'aparició a la seva vídua, immortalitzada en una cançó que ens ha arribat fins avui, i la condemna a vagar en el seu cavall, amb la seva gossada i les ànimes damnades, per tota l'eternitat.

Les diverses versions i llegendes en què el Comte Arnau és protagonista ens mostren diversos aspectes i personalitats sobreposades, que no es troben totes 
en el mateix indret, sinó que han estat acumulades després de recollir-les i unificar-les, tot i ser originàries de diferents llocs. Molts dels episodis sembla que procedeixin de diferents moments històrics, però tots ens mostren com se li han atribuït alguns fets i personatges que han impressionat els pobles on hi ha tradicions sobre el Comte Arnau, sense pensar que pertanyien a períodes temporals diferents. Aquesta es una configuració pròpia de les llegendes. D'aquesta forma, ha anat creixent la figura del Comte Arnau, generació rere generació, i necessitaria no una, sinó moltes vides per haver pogut omplir tots els fets que se li atribueixen.

L'anacronisme també s'observa en les històries atribuïdes al Barón d'Espés que, essent un personatge crescut a l'edat mitjana, porta una espingarda, arma de foc molt posterior. La seva història també recull l'alliberament de la seva dominació per part d'un veí, que va córrer pels boscos i muntanyes per poder arribar a temps a l'ajuntament per donar testimoni i signar.

És a dir, tots dos personatges formen un caramull d'episodis brodats en diferents temps per les generacions que han servat aquests mites com a expressió del seu sistema de valors.

Rossend Serra i Pagès va ser el primer investigador que es va qüestionar la personalitat múltiple del Comte Arnau, i és a ell a qui devem l'aportació de les comparacions amb altres herois mítics, perquè els episodis de la seva història ajuntaven un munt de personatges de diverses èpoques, amb trets contradictoris.

L'inici de la seva recerca rau en l'esforç anterior dels historiadors per encabir un mite en un marc històric precís i dotar l'heroi d'una personalitat historiogràfica concreta, sense comptar amb el procés mític que arrossega darrere seu, els personatges i els fets que cada generació que els viu considera compatibles amb la figura formada, segons les circumstàncies i els sostres d'aculturació a què està sotmesa. Així, una intensa evangelització portarà a una demonització d'un déu o un heroi anterior, per citar un dels processos coneguts. Tal com ens diu Serra i Pagès, va començar la seva malfiança respecte al P. Pau Parasols Pi, un dels primers estudiosos del Comte Arnau, perquè aquest havia forçat els episodis del mite per desplaçar-lo del s. XI, on fins aleshores se l'ubicava, i situar-lo en el s. xIII, de manera que no coincidís la tradició de disbauxa amb les monges d'un suposat convent de Sant Amanç, amb les disbauxes històriques i documentades de les monges de Sant Joan de les Abadesses del s. XI, ja que Pau Parasols era de Sant Joan de les Abadesses i volia deslliurar la seva vila de qualsevol taca moral i el Comte Arnau era considerat maleït i condemnat, i més encara per un capellà.

Serra i Pagès va incidir davant de l'actuació interessada de Pau Parasols en el curs de la seva recerca en trobar en el curs del seu treball de camp episodis del mite que el situessin correctament, i es va trobar amb una sorpresa, perquè va recollir narracions i fets del Comte Arnau que l'ubicaven no ja en el s. XIII ni en el s. XI, sinó en el segle IX, en la primera reconquesta. Efectivament, el Comte Arnau apareix fent front en algunes narracions a la invasió sarraïna des de les coves de Ribes, d'altra banda, habitades per encantàries. També la toponímia de diversos llocs de la tradició arnaldiana no sols conserven el record de les seves disbauxes, sinó que fan al-lusions a les batalles de la Reconquesta que ell havia dirigit, com la Coma Armada, per exemple.

Serra i Pagès continua volent trobar un personatge historiogràficament autèntic, malgrat reconèixer la multiplicitat de personatges que s'anaven empeltant els uns amb els altres, en el pas de les generacions portadores del mite, i veient com 
en el Comte Arnau s'hi ajuntaven vells mites europeus de diferents sostres culturals.

Aquest interès dels historiadors per conèixer quin personatge concret podia haver generat la cadena de narracions, arriba fins als nostres dies, i Prim Bertran, l'any I992, en el seu estudi de la casa de Mataplana, on el Comte Arnau tenia el castell (que dataria en el s. XI), assenyala un possible candidat, Ramon d'Urtx i Mataplana que, en el seu testament, de I297, menciona dos llibres que enumeraven totes les injustícies que ell i la seva mare, na Blanca, havien comès i deixa 59.0oo sous per reparar-les totes, ja que diu que tota la seva hisenda no arribaria a compensar-les.

Pel que fa al Barón d'Espés, els historiadors han marcat un personatge del s. XIII com el generador del mite, sobretot perquè hi coincidien alguns trets atribuïts al Barón d'Espés de la llegenda. Es tracta d'un dels molts Bernat famosos en la Ribagorça, ja que Bernat sembla que és un nom recorrent i definidor de la noblesa dirigent del Comtat, i que va tenir, com els seus antecessors, una gran connexió amb el monestir d'Ovarra. L'any i225 Bernat d'Espés dóna a Ovarra Santa Maria de Calvera. L'any I232 fa altres donacions a Ovarra i el document de donació acaba dient «que Sta. Maria li serveixi d'ajut i protecció quan surti d'aquest món, i si algú contradiu aquestes ofrenes que la mateixa Mare de Déu li imposi el càstig corporal, Amen». Aquest Bernat és el que se suposava que reposava a Ovarra en un sepulcre gòtic, policromat, del s. XIV, desaparegut d'Ovarra després de I908. No obstant això, les recerques posteriors, basant-se en l'heràldica que figura en l'escultura sepulcral, han descobert que es tractava de Ramón de Peralta i Espés, mort l'any I348, i que va ser capità dels exèrcits d'Aragó. Dos dels lleons (o gossos, segons tradició popular) que suportaven el sepulcre es conserven en el Museu Diocesà de Barbastre.

Però la llegenda fa referència a diverses etapes culturals, i un dels trets més importants és el d'haver afavorit la construcció del monestir d'Ovarra, que, segons Duran Gudiol, data del segle Ix, però que altres autors hi situen una comunitat incipient en el segle VII. La construcció d'un monestir d'aquestes característiques instaurava un nou ordre econòmic de roturació i repoblació, i la població antiga ho veia com la destrucció de l'ordre anterior, que abastava el paisatge sagrat i les vies de comunicació protegides i establertes en relació amb la seva topografia sagrada, en relació amb les seves divinitats i poblades de genis i altra fauna espiritual. Per això la població antiga, qualificada posteriorment com a «les bruixes», l'amenaça des del Turbó: «Si a Obarra vas, a Espés no hi tornaràs més». No hem d'oblidar que, en el camí d'Espés, hi ha el coll d'Ares, cristianitzat per una ermita de la Mare de Déu del mateix nom, i que era lloc de reunió i dansa de la població antiga, en aquest cas, anomenada com encantaries en les narracions locals. Recordem també, que en l'altra vessant del Turbó hi ha el coll de Fades, una altra denominació local per designar les poblacions antigues.

Ara bé, malgrat que el Bernat d'Espés del s. Xıı presenta uns trets centrals del mite, hi ha altres personatges de la mateixa casa, i de la casa comtal de Ribagorça, que també podrien haver contribuït a la formació de la narració. De fet, la seva tensió del poder d'aquestes dinasties, amb els pobladors antics i forçats, en part, a refugiar-se a les muntanyes menys accessibles per la construcció del monestir d'Ovarra, es remunta a uns quants segles enrere. 
Ovarra està situat al costat d'una antiga calçada romana que travessava els Pirineus, de manera que la romanització ja va constituir una agressió, tant per a l'entorn com per als pobladors de la zona. Molt a prop del monestir, hi havia el castrum ripacurtiensis, seu dels comtes ribagorçans, que van ajudar a l'edificació d'Ovarra, a la seva reconstrucció i que van foragitar els exèrcits sarraïns. Ovarra va ser, com Ripoll per a la casa comtal catalana, o San Juan de la Peña per a la casa reial d'Aragó, el santuari oficial i panteó de les seves dinasties. De fet, Ovarra, en la seva fase inicial, és anterior al s. viI, comprovat per la descoberta, arran de la darrera restauració, d'algun element visigòtic que la construcció encara conserva.

Hi ha una segona etapa de reconstrucció d'Ovarra, sota la política carolíngia, després de la primera devastació sarraïna, en els segles VIII i IX. Més tard, torna a ser devastat el monestir en el s. XI, per les tropes d'Abd-Al-Malik (IOo6). És a dir, hi ha força episodis de construcció i devastació que poden haver proporcionat material per al desenvolupament de la llegenda.

Altres Bernats que poden haver participat en la formació del mite són el Comte Bernat, de Ribagorça, enterrat a Ovarra (920), fill de Ramon I (assassinat l'any 872), i que va recuperar moltes de les terres envaïdes per Al Tawill. Es parla d'ell com a fundador d'Ovarra, malgrat que fos només una refundació. Sumada la personalitat d'aquest Bernat a la de Bernardo del Carpio, heroi de Roncesvalles, i altres, forma part d'un cantar de gesta, datat del s. XI, ampliat en el s. XIII i restaurat per Milà i Fontanals, en el s. XIX, en La Cançó del Pros Bernat.

L'assassinat de Gonçal de Ribagorça, la devastació de Ioo6, l'extinció de la casa ribagorçana amb la mort de Guillem Isarn l'any IoI7, s'ajunta en el terreny espiritual amb la imposició del ritus gregorià, que va sacsejar també l'univers de la zona. És a dir, hi ha una colla de fets i personatges que van anar teixint un mite que reuneix característiques semblants al Comte Arnau al Ripollès. A cada nou horitzó temporal, la gent empeltava el mite a un personatge real, que s'hi ajustava en algun tret. Així, podem anar resseguint tota la nissaga des d'horitzons molt llunyans fins al s. XIX, quan encara la gent atribuïa fets coetanis o proppassats al Barón d'Espés o al Comte Arnau (com l'episodi de l'alliberament de la propietat indirecta i el cens del Barón d'Espés, o la gasiveria del Comte Arnau en reclamar el vestit de bateig que havia regalat a un fillol, que havia mort poc després).

La relació ambivalent d'ambdós herois amb la població antiga vençuda fa que, com passa amb els personatges híbrids, se'ls rebutgi per ambdós costats, i la nova població, tot demonitzant l'anterior, acaba atribuint-li les seves morts. Aquest seria un primer punt de la personalitat d'ambdós personatges: el fet de pertànyer al poble antic, però afavorint l'entrada i assentament dels nous models econòmics, poblacionals i religiosos. D'aquesta manera, passen a ser mal vistos per les dues parts, pels pobles antics, caçadors i recol-lectors, amb agricultura i ramaderia incipient, ja que afavoreixen el nou sistema, i per la nova classe dominant, de la mà d'un nou poder eclesiàstic i civil, que mai no els considerarà com un dels seus, sinó que tractaran de desprestigiar-los per totes bandes, ja que veuen en ells que continuen formant part del poble antic, vençut i esfuriat cap a l'interior i als terrenys menys productius, sempre suspectes de rebel-lió i d'heretgia, que, com sabem, sempre s'acaba unificant en el sac comú de la bruixeria i el pacte amb el dimoni. En aquest sentit, Serra i Pagès inclou la relació del Comte Arnau amb la Fada de Prestill. Pel que fa al Barón d'Espés, el seu tracte de favor a la casa La Mora 
ens assenyala una denominació molt utilitzada per designar els pobles antics a Europa, la de moros, fins i tot abans de la invasió sarraïna.

Un segon aspecte per a la reflexió és l'atribució a aquests personatges d'un paper de depredadors sexuals, tret que Serra i Pagès considerava com a atiat en certa manera per la jerarquia eclesiàstica, que demonitzava el Comte Arnau per la seva relació orgiàstica amb les monges de Sant Amanç o les de Sant Joan de les Abadesses, monestir que fou realment suprimit arran de la vida poc santa que portaven les monges. La consideració i la fama de ser uns depredadors sexuals es converteix en una de les característiques atribuïdes a aquests herois, per desacreditar i desqualificar antigues creences i configuracions socials, de les quals aquests herois mítics eren la continuació, i es transmetien els trets d'antigues divinitats descavalcades per les noves formes religioses i polítiques, després d'haver estat empeltats en personatges nobles feudals.

Antonio Martínez descriu la mort del Barón d'Espés causada perquè Bernardo, Barón d'Espés, estava enamorat d'una novícia d'un monestir, que devia ser el Beateri de Brallans, dependent d'Ovarra, al terme de Tor-la-ribera, i a prop d'on ara hi ha el balneari de Las Vilas del Turbón. Els monjos i els habitants del lloc el van esperar al pas de la Croqueta, quan tornava de cacera cap al monestir, i el van tirar daltabaix del cingle i, a més, encara li van tirar pedres des de dalt i van deixar anar els mastins perquè acabessin la feina. Quan es va voler saber qui havia estat, la gent ho atribuiia a la població anterior, refugiada a la muntanya, a la qual anomenaven les «bruixes» del Turbó i a les quals culpaven de totes les malvestats. Una altra versió ens conta que el Barón d'Espés visitava la muller d'un moliner i que aquest, un dia, el va esperar i el va matar.

La demonització i rebuig d'aquesta nissaga de personatges (que van anar enriquint-se amb la suma d'històries, primer de déus, després d'herois, nobles, pobles vençuts) per part de les autoritats eclesiàstiques i el poder polític té una derivació diferent en el poble, que s'apropia i transforma el rebuig del poder i l'atribució de malvestats, basant-lo no en la característica de depredadors sexuals, sinó en el fet de ser persones poderoses i riques que actuen contra la comunitat. No se'ls assimila sempre amb el dimoni com faran les autoritats eclesiàstiques, sinó que són condemnats a vagar pel mal comès contra el poble, com a patrons. A Sardenya, Cristina Cocco ha recollit la configuració del personatge del ric condemnat acompanyat d'un cavall blanc, que representa el difunt, que corre fuent pel camp i el paisatge, sembrant el terror, tant de nit, amb la seva ràpida carrera salvatge, com de dia, a la plaça de les poblacions, convertint-se en una flama, quan qui ho veu resa unes oracions determinades. ${ }^{2}$

El paral-lelisme amb la figura del Comte Arnau, condemnat per mesures mal rasades i per soldades mal pagades, acompanyat del cavall, corrent desbocat per les nits, i voltat de flames, és ben evident, i es pot afirmar que hi ha un sostre d'interpretacions populars que transformen els arguments de la condemna que en la jerarquia eclesiàstica i política foren el caràcter de depredador sexual i un suposat pacte amb el dimoni, en l'opressió i abús del poderós cap a la seva gent.

També, en aquest sentit, l'actuació del personatge a favor de la rompuda del terreny, desfent antics paratges i camins, a favor del repoblament i la propietat

2. Aquest material recollit a Sardenya forma part de la recerca duta a terme en el marc de la seva tesi doctoral («La creencia en la bilocación en Cerdeña»), actualment en fase d'elaboració. 
dels grans monestirs, serà el motiu popular de la seva mort. Així, les «bruixes» del Turbó podien amenaçar el Barón d’Espés: «Si a Obarra vas, a Espés no hi tornaràs més.»

I, no obstant això, persisteix en el poble l'ambivalència dels personatges, que perduren com a centre d'identitat de la comarca, malgrat els esforços dels poders per obliterar-lo. El Barón d'Espés va deixar marcat el seu cos, assegut, en una roca, en el camí d'Espés a Ovarra, i encara es podia veure a mitjan segle Xx, abans de ser envaït l'indret per la bardissa. Pel que fa al Comte Arnau, va deixar les empremtes dels seus peus i les de l'abadessa en una roca, així com la de les peülles del seu cavall. Aquesta interpretació de la identitat de la comarca s'expressa, fins i tot, malgrat els esforços del poder per obliterar-la. Així, el monument de Sant Joan de les Abadesses, dedicat a Guifré el Pilós, de la nissaga afavorida pel poder carolingi, per sobre de la nissaga local, és considerat pel poble com a representant el Comte Arnau, i els lleons del sarcòfag d'un dels barons d'Espés, que hi havia a Obarra, abans de ser espoliat, són, segons el poble, la representació palesa dels gossos o «cochos» del Baró.

Ara, en tercer lloc, anirem un pas més enllà, i veurem com en són, de fondes, les arrels del mite que ajunta el Comte Arnau i el Barón d'Espés, i com la demonització i baixada del mite d'aquests personatges a l'inframón es correspon amb l'aculturació religiosa i política de les diferents onades de poder, que han imposat creences i formes de vida.

Partim, doncs, d'un universal psicosocial que fa descendir a l'inframón els déus i herois que en sostres culturals anteriors pertanyien al món celestial o superior. Ens fixarem, sobretot, en un dels trets característics del Comte Arnau, el de la cacera infernal com a càstig genèric al Mal Caçador, així com veurem quins elements del Barón d'Espés formen part d'aquest aspecte del mite, més diluïts però també presents, com la seva afecció a la caça, el seu cavall blanc, els gossos que l'acompanyen i finalment se'l mengen. La narració, en el cas del Comte Arnau, coincideix amb la forma canònica demonitzada. És a dir, estant el Comte oint missa, en el moment de la Consagració, els seus gossos es posen a perseguir una llebre i ell no pot resistir la temptació i els segueix. És condemnat a perseguir la caça, eternament, i la cavalcada salvatge després de mort ajunta les relacions sacrílegues amb l'abadessa Adelaisa, a la qual porta a la gropa del seu cavall, tots els seus gossos i altres ànimes damnades, que no cessen de córrer eternament produint l'espant en qui els sent passar en una nit de tempesta, tal com afirmaven els informants de Serra i Pagès. Els gossos no són els causants de la seva mort, com passa amb el Barón d'Espés, sinó els gats, animals demonitzats per excel·lència, transformació de bruixes i dimonis. Però l'episodi del Mal Caçador serveix com a argument per a la cacera salvatge i el seguici infernal del Comte.

Abans de la difusió del Cristianisme i l'establiment de l'estructura eclesiàstica, la gran majoria de cultures europees reconeixien en la seva geografia del Més Enllà, d'una banda, uns herois psicopomps, que podien prendre la forma d'animalsguies, com la cigonya, la grua, l'àliga o el cavall, i que es cuidaven del transport de les ànimes, sobretot dels difunts a l'estadi de plenitud final d'avantpassats. A poc a poc, aquests animals símbols es transformen o completen amb personatges divins o heroics que duran a terme aquest transport, i en llur cristianització se substitueixen per sants, com Sant Martí, Sant Jaume, Sant Jordi i altres, que ajunten al cavall 
blanc la figura d'un heroi que portarà les ànimes al Cel, a través de la Via Làctia o camí de Sant Jaume.

Però en la cosmovisió dels pobles europeus queden també les ànimes que encara vaguen pel món i que no arriben al país dels avantpassats. Aquestes ànimes són replegades per herois psicopomps però d'una presència ambivalent, ja que poden arrossegar els vivents en aquesta marxa per l'aire, i produeixen por, per això se'ls sent en nits de tempesta. De quina manera la tasca dels herois psicopomps es divideix entre transformar-se en sants, d'una banda, i de l'altra, demonitzar-se i acabar conduint la processó de damnats depèn de cada cultura i el procés de l'aculturació religiosa que hagin recorregut, així com de la persistència d'aquest estadi intermedi, ambivalent, de les ànimes que vaguen pel món.

Des de la preocupació teològica cristiana, la consideració d'un lloc intermedi entre el Cel i l'Infern, per netejar les ànimes dels seus pecats després de la mort, és a dir, quan ja no s'és a temps per merèixer, acaba per la configuració d'un lloc, el purgatori, a finals del s. XII, on les ànimes poden rebre auxilis espirituals dels seus familiars i amics, amb oracions, almoines i rituals específics. Però les antigues creences en altres configuracions del Més Enllà continuen vives, tot i que els mites que hi fan referència i els herois que les sustenten passen d'una ambivalència o d'una conducta positiva a una de necessariament negativa, però aquesta mateixa possibilitat de combinar-se amb nous i antics mites els assegura la pervivència.

Es tracta, com hem dit, d'un universal psicosocial, present tan bon punt hi ha la confrontació de dues cultures, una dominant i l'altra vençuda. Encara que els déus i la història dels vencedors s'imposi sobre els déus i la història dels vençuts, aquests conserven la seva cosmovisió anterior, encara que degradada i llençada a l'inframón. La demonització o la humanització dels antics déus i herois els serveix per servar-ne el record, però també per fer por als vencedors, amb els trets negatius amb què els han revestit.

I és ací on anem a veure un exemple de divinitat i heroi que tenia aquesta funció de transportador d'ànimes, per veure com el Comte Arnau i el Barón d'Espés entren dins de la seva nissaga i evolució.

La recerca d'antecedents divins en la conducció d'ànimes ens porta necessariament fins a Odin, el déu germànic i dels pobles escandinaus, amb diferents noms, segons cada zona. El llop gris Fenrir finalment mata Odin en l'etapa del Ragnarok o declivi dels déus. Odin se'ns presenta com a déu psicopomp, acompanyat d'ànimes que vaguen, conduint una cacera fantasmal, amb genets i gossos, en el cel de tempesta, i sentir-lo fa esfereir, ja que és un mal presagi.

La cacera salvatge amb ànimes que vaguen pel món és un mite estès pel nord, oest i centre d'Europa. No es tracta de pensar que el culte a Odin s'estenia fins als Pirineus, una qüestió que necessitaria proves arqueològiques, sinó que, en un sostre preromà, un tipus de divinitat com la d'Odin podia haver estat compartida per molts pobles europeus, amb altres noms i peculiaritats distintives, però amb alguns trets afins. Amb l'aculturació religiosa, la personalitat de l'antic déu i alguns dels seus trets van passar a empeltar-se en personatges històrics rellevants, amb els quals podien associar-se emocionalment en el poble que així els ajuntava. La cacera salvatge va passar a ser guiada no per un déu com Odin, sinó per una figura històrica, com Teodoric, Carlemany, el Rei Artús, Caín, Herodes i molts altres. Més tard, a Anglaterra se l'associa amb el món antic de les fades. Alguns d'aquests 
personatges apareixen amb una llum blava al voltant, i recordem que el Comte Arnau apareix voltat de flames.

En conclusió, penso que podem dir que sobre una divinitat antiga, transportadora i conductora d'ànimes, amb característiques semblants a moltes divinitats europees precristianes i preromanes, les successives onades conqueridores i els canvis religiosos que es van imposar a les poblacions antigues van anar demonitzant el personatge, que s'acaba empeltant en figures locals, com ara nobles destacats i locals, i els seus trets inicials finalment són demonitzats pel poder polític i eclesiàstic, tot atribuint-li una voracitat sexual desmesurada i, fins i tot, un pacte amb el dimoni. La seva funció de conductor d'ànimes es transforma en càstig per un sacrilegi relacionat amb la seva afecció a la caça, o per la seva relació amb poders infernals o de bruixeria. Però el poble, influenciat per aquesta baixada a l'inframón, acaba demonitzant un altre tret dels nobles que s'han sumat a la seva figura, el de l'explotació desmesurada dels seus vassalls, com un mal patró. En el cas del Comte Arnau i del Barón d'Espés, els antecedents divins es transformen en personatges locals, amb morts violentes, en què els gossos tenen un paper central, i així la cacera del Mal Caçador minimitza el transport de les ànimes, fet central en la visió antiga del Més Enllà.

I ara, com a epíleg, voldria mostrar també l'altre llarg camí sofert pel sepulcre del Barón d'Espés, tot endinsant-me en un altre dels misteris que envolten el Barón d'Espés, a qui s'atribueix popularment el sepulcre que estava al monestir d'Ovarra, però que pertany a un dels diversos personatges que es van sumar a la seva figura primitiva, a Ramón de Peralta i Espés. Aquest sepulcre, del s. XIV, va ser admirat in situ per l'expedició artística encapçalada per l'arquitecte Puig i Cadafalch, que el va fotografiar, juntament amb altres objectes artístics i l'antic altar d'Ovarra, l'any igo8.

Només se sabia que, uns anys després, havia desaparegut i havia estat substituït per una còpia de guix, que també va ser destruïda l'any I936, amb gran sorpresa dels qui la van destruir, perquè no s'esperaven que no fos l'original.

Sabem que l'any I933 el sepulcre estava en possessió de la Spanish Art Gallery, una galeria d'art que Lionel Harris havia obert a Londres, a I907, que també en tenia una altra a Madrid, des d'on dirigia les seves recerques d'obres d'art, més o menys lícites. El seu fill, Thomas Harris (I908-I964 a Mallorca), fou un artista reconegut en molts camps, com la pintura, els vitralls, l'escultura, els tapissos, però també va ser marxant d'art, sobretot d'art espanyol, primer per a l'empresa dels seu pare i, després de la seva mort, va continuar el negoci de compravenda d'art. En la Segona Guerra Mundial, va fer d'espia per als aliats, al costat d'un altre espia famós, l'anomenat Garbo.

El sepulcre de Ramón de Peralta i Espés va quedar exposat temporalment, juntament amb altres obres d'art hispànic, a la galeria d'art Grosvenor House, de Londres, però la seva localització en la Spanish Art Gallery és la més probable, fins que Sir William Burrell la va comprar l'any i953. En la documentació que l'acompanyava, es deia que el sepulcre havia estat extret de les runes de l'església de Peralta, prop de Barbastre (no especificava si era Peralta de la Sal o Peralta de Alcofea). Però aquesta informació que donaven els venedors era errònia, ja que l'expedició de Puig i Cadafalch l'havia fotografiat in situ, a Ovarra.

Sir William Burrell va aplegar la més gran col-lecció privada d'art europeu, més de 8.000 peces, i en el testament, ell i la seva muller, Lady Constance Burrell, 
la van llegar, l'any I944, a la ciutat de Glasgow, amb la condició que s'ubiqués a I6 km de la pol-lucionada ciutat, per tal d'evitar la degradació dels materials de les obres d'art. Aquestes condicions van trigar anys a complir-se, fins a I983, però avui, el museu constitueix una obra important de l'arquitectura contemporània, a més del tresor que acull.

El punt fosc passa entre els anys I908 i I933, però la personalitat de Lionel Harris i del seu fill, Thomas Harris, voltant per Espanya per cercar obres d'art per a la seva galeria, ens fa pensar que possiblement ací és on es produeix l'espoli o compra amb avantatge, en detriment del patrimoni d'Ovarra i la gent de la Ribagorça. No van viatjar a Londres els lleons que sostenien el sepulcre, dos dels quals, mutilats, els va retirar el bisbat de Barbastre, l'any I958, i ara són a la reserva del seu Museo Diocesano, però del tercer lleó no se'n sap el destí.

Per a la llegenda del Barón d'Espés no importa que el sepulcre pertanyi o no a algun baró que fornís la continuïtat de la narració amb la seva història, ni que els animals que sostenien el sepulcre fossin lleons o gossos. Per a la gent d'Espés i de la Ribagorça, són la prova que al Barón d'Espés se’l van menjar els seus «cochos».

\section{Referències bibliogràfiques}

Duran Gudiol, Antonio (1975): De la Marca Superior de Al-Andalus al Reino de Aragón, Sobrarbe y Ribagorza. Osca: Caja de Ahorros de Zaragoza, Aragón y Rioja.

GALtier, Fernando; Roberto Benedicto (20I3): Santa María de Obarra. Saragossa: Mira Eds.

IgLesias CostA, Manuel (I975): Obarra. Jaca: CSIC.

Martínez, Antonio (20II): «La Leyenda del Barón de Espés». Diario del Alto Aragón (24.04.2OII).

QuintanA, Artur (2007): «El Mite del Comte N'Arnau a la Ribagorça?». Dins Xandra. Estudis aragonesos de llengua i literatura. Calaceit: Institut d'Estudis del Baix Cinca / Associació Cultural del Matarranya, p. 28I-302.

SERrA I PAGÈS, Rossend (I9Io-29): «Materials de recerca sobre el Comte Arnau». Dins «Com han sigut fetes les Investigacions». Arxiu Històric de Barcelona, Carpeta 4I, plec I. 